\section{Kidney Blood Pressure Research}

\title{
Lung Dysfunction and Mortality in Patients with Chronic Kidney Disease
}

\author{
Hideyuki Mukaia Pei Ming ${ }^{b} \quad$ Bengt Lindholma Olof Heimbürger $^{\mathrm{a}}$ Peter Baranya \\ Peter Stenvinkela Abdul Rashid Qureshia \\ aDivision of Renal Medicine and Baxter Novum, Department of Clinical Science, Intervention and \\ Technology, Karolinska Institutet, Campus Flemingsberg, Stockholm, Sweden, 'birst Teaching Hospital \\ of Tianjin University of Traditional Chinese Medicine, Tianjin, China
}

\author{
Key Words \\ GFR categories $•$ pulmonary function $\bullet$ mortality
}

\begin{abstract}
Background/Aims: Lung dysfunction associates with increased mortality but the impact of chronic kidney disease (CKD) is less clear. We evaluated lung function and its association with mortality among individuals with normal to severely reduced glomerular filtration rate (GFR). Methods: 404 individuals representing GFR category G1 $(n=31 ; G F R>90 \mathrm{~mL} / \mathrm{min} / 1.73$ $\left.\mathrm{m}^{2}\right), \mathrm{G} 2(\mathrm{n}=46), \mathrm{G} 3(\mathrm{n}=33), \mathrm{G} 4(\mathrm{n}=49)$ and $\mathrm{G} 5\left(\mathrm{n}=245 ; \mathrm{GFR}<15 \mathrm{~mL} / \mathrm{min} / 1.73 \mathrm{~m}^{2}\right)$ underwent spirometry yielding lung function indices forced vital capacity (FVC), forced expiratory volume in the first second $\left(\mathrm{FEV}_{1}\right)$ and peak expiratory flow (PEF). Associations of lung function indices expressed as percentages of predicted values (\%FEV ${ }_{1}$ \%FVC and \%PEF) with 5-year mortality were analyzed by competing-risk regression models. Results: The prevalence of obstructive ( $6 \%$ in $\mathrm{G} 1$ and $11 \%$ in $\mathrm{G} 5$ ) and especially restrictive (9\% in $\mathrm{G} 1$ to $36 \%$ in G5) lung dysfunction increased with declining GFR and with higher comorbidity burden. In patients $(n=22)$ with protein-energy wasting, inflammation and cardiovascular disease, the prevalence of restrictive lung function was $64 \%$. The highest tertiles of $\% \mathrm{FEV}_{1}$ and $\% \mathrm{FVC}$ associated with lower subhazard ratios (sHR) for all-cause mortality, 0.49 (95\% CI, 0.27-0.88)) and 0.56 (95\% CI, 0.32 0.98 ), and that of \%FEV 1 also with lower cardiovascular mortality risk (sHR $0.16 ; 95 \% \mathrm{CI} 0.04$ 0.69 ) after adjusting for multiple confounders. Restrictive lung dysfunction ( $F E V_{1} / F V C \geq 0.70$, and \%FVC < 80) associated with increased mortality risk (sHR 1.80, 95\%CI, 1.04-3.13) while the association with obstructive lung impairment was not statistically significant. Conclusion: Lung dysfunction and in particular restrictive lung dysfunction associates with degree of renal function impairment and presence of comorbidities, and is an independent predictor of increased mortality in CKD patients.




\section{Kidney Blood Pressure Research}

\section{Introduction}

Chronic lower respiratory disease is the third leading cause of death in the United States [1] where in the general population $7 \%$ were reported to have restrictive and $14 \%$ obstructive lung dysfunction [2]. The lungs may be severely affected by advanced chronic kidney disease (CKD) [3]; however, the prevalence of lung dysfunction is increased even in patients with CKD stage 1-4, to $10 \%$ for restrictive and 16\% for obstructive lung function according to the National Health and Nutrition Examination Survey (NHANES) 2007-2012 [4]. As glomerular filtration rate (GFR) falls, pulmonary edema and respiratory muscle dysfunction become more common due to fluid retention and metabolic, endocrine and cardiovascular alterations $[5,6]$. Not only GFR but also urinary protein excretion may be linked to worsening lung function [7]. However, lung function assessment is not a routine clinical practice in the management of patients with CKD and the prevalence, characteristics and clinical implications of restrictive and obstructive pulmonary dysfunction in individuals with different degree of renal function impairment are not well characterized.

In the general population, impaired lung function is known to increase the risk of cardiovascular morbidity and mortality $[8,9]$. In contrast, there are few reports on links between pulmonary dysfunction and mortality in CKD patients $[10,11]$. In one study, reduced forced vital capacity (FVC) was independently associated with increased mortality risk in non-dialyzed CKD 5 patients [10] while in another study low forced expiratory volume in the first second $\left(\mathrm{FEV}_{1}\right)$ was not an independent risk factor for mortality in patients undergoing dialysis [11]. The association between pulmonary dysfunction and mortality across different GFR categories remains a largely unexplored area.

In the present study, we analyzed pulmonary function in relation to specified GFR categories in carefully phenotyped individuals with normal to reduced renal function and assessed associations of lung dysfunction with all-cause and cardiovascular disease (CVD) related mortality. To the best of our knowledge, this is the first comprehensive study of the association of impaired pulmonary function with mortality in individuals with normal to severely reduced renal function, GFR categories 1-5.

\section{Materials and Methods}

\section{Patients and study design}

Pulmonary function was investigated by spirometry in 404 clinically stable patients with G-1 ( $\mathrm{n}=31$; GFR >90mL/min/1.73 m²), G-2 ( $\mathrm{n}=46), \mathrm{G}-3$ (n=33), G-4 ( $\mathrm{n}=49)$, and G-5 ( $\left.\mathrm{n}=245 ; \mathrm{GFR}<15 \mathrm{~mL} / \mathrm{min} / 1.73 \mathrm{~m}^{2}\right)$. Exclusion criteria were age $<18$ years, acute renal failure, signs of overt clinical infection and unwillingness to participate. Informed consent was obtained from each individual. The Ethics Committee of the Karolinska Institute (EPN) at the Karolinska University Hospital Huddinge, Stockholm, Sweden, approved study protocols. The studies were conducted in adherence to the Declaration of Helsinki.

The GFR categories were defined according to current guidelines based on estimated GFR (eGFR) calculated according to the CKD-EPI (CKD Epidemiology Collaboration) equation [12]. Patients were classified into GFR categories 1-5 according to the National Kidney Foundation's K/DOQI guidelines [13]. The clinical and laboratory characteristics of the patients in the different GFR categories are shown in Table 1. The cohorts and the underlying causes of CKD are briefly described below:

G-1 individuals ( $n=31)$ and G-2 individuals $(n=46)$ were recruited from a population-based sample of individuals from the Stockholm region, randomly selected by Statistics Sweden (a government agency), who served as control subjects for a study on malnutrition, inflammation and atherosclerosis in patients with CKD 3-4, the PRIMA study [14].

G-3 individuals $(n=33)$ were recruited from PRIMA study $(n=31)$ and control subjects in the PRIMA study $(n=2)$. The causes of CKD were chronic glomerulonephritis $(n=6)$, diabetic nephropathy $(n=4)$, others $(n=21)$ and unknown $(n=2)$. 


\section{Kidney Blood Pressure Research}

Mukai et al.: Pulmonary Dysfunction and Survival in CKD

G-4 individuals $(n=49)$ were recruited from an ongoing study of associations between malnutrition, inflammation and atherosclerosis in CKD patients initiating dialysis therapy, the MIA study [15] ( $n=6)$, and from the PRIMA study ( $n=43)$. The causes of CKD were chronic glomerulonephritis $(n=12)$, hypertension and reno-vascular disease $(n=2)$, diabetic nephropathy $(n=8)$ and others $(n=27)$.

G-5 individuals $(n=245)$ were recruited from the MIA study [15] $(n=224)$, and from the PRIMA study [14] $(n=21)$. The causes of renal failure included: chronic glomerulonephritis $(n=54)$, hypertension and reno-vascular disease $(n=55)$, diabetic nephropathy $(n=74)$ and others $(n=62)$. At the time of baseline investigation, 65 patients had been on hemodialysis $(n=44)$ or peritoneal dialysis $(n=21)$ dialysis for a median time of 11 (2-36) days.

All anthropometric, biochemical and clinical measurements were performed on the same day as - or close to - the investigation of lung function. Lung function assessments among the $\mathrm{G}-5(\mathrm{n}=245)$ patients were repeated after one year $(n=130)$ and after two years $(n=65)$ in some of the patients. At baseline, all patients including G-5 patients, were treated conservatively, while subsequently almost all G-5 patients initiated dialysis treatment $(n=237)$ and many of them underwent renal transplantation $(n=112)$ during the follow up period of five years. In hemodialysis patients, investigations were performed on dialysis-free day. Peritoneal dialysis patients were investigated with peritoneal dialysis fluid in the peritoneum cavity.

Table 1. Clinical and biochemical characteristics and lung function data in 404 patients with GFR categories G1 - 5. Continuous variables are presented as median (10 - 90 percentile). Categorical variables are presented as number (n)/percentage (\%). Abbreviations: Mean BP, mean blood pressure; GFR, glomerular filtration rate; Total BMD, Total bone mineral density; SGA, Subjective global nutritional assessment; HDL, highdensity lipoprotein; intact-PTH, intact parathyroid hormone; hsCRP, high-sensitivity C-reactive protein; IGF1, insulin-like growth factor-1; IL-6, interleukin-6; TNF, tumor necrosis factor; ACEi, angiotensin-converting enzyme; ARB, angiotensin 2 receptor blocker; FVC, forced vital capacity; FEV $_{1}$, forced expiratory volume in

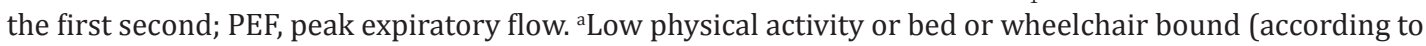
questionnaire where patient reported one of four domains: 1) exercise frequently, 2) normal activity, 3) low activity, or 4) bedridden or wheelchair bound); ${ }^{\circ} \%$ HGS, Handgrip strength as percentage of values for CKD 1 and 2. Obstructive lung function: FEV1/FVC $<0.70$. Restrictive lung function: FEV1/FVC $\geq 0.70$ and $\%$ FVC $<80$

\begin{tabular}{|c|c|c|c|c|c|c|}
\hline Demography and clinical characteristics & $\begin{array}{c}\mathrm{G} 1 \\
(\mathrm{n}=31)\end{array}$ & $\begin{array}{c}\mathrm{G} 2 \\
(\mathrm{n}=46)\end{array}$ & $\begin{array}{c}\mathrm{G} 3 \\
(\mathrm{n}=33) \\
\end{array}$ & $\begin{array}{c}\mathrm{G} 4 \\
(\mathrm{n}=49)\end{array}$ & $\begin{array}{c}\text { G5 } 5 \\
(\mathrm{n}=245)\end{array}$ & Pvalue \\
\hline Age (years) & $59(38-69)$ & $64(49-77)$ & $\frac{(11-53)}{61(30-74)}$ & $60(37-75)$ & $56(34-69)$ & $<0.001$ \\
\hline Males, n (\%) & $22(71)$ & $32(70)$ & $26(79)$ & $33(67)$ & $149(61)$ & 0.21 \\
\hline Diabetes mellitus, $\mathrm{n}(\%)$ & $2(6.5)$ & $1(2.2)$ & $8(24.2)$ & $20(40.8)$ & $83(33.9)$ & $<0.001$ \\
\hline Cardiovascular disease, $\mathrm{n}$ (\%) & $3(9.7)$ & $2(4.4)$ & $9(27.3)$ & $13(26.5)$ & $84(34.3)$ & $<0.001$ \\
\hline Smoker, $\mathrm{n}(\%)(\mathrm{n}=28 / 44 / 29 / 42 / 200)$ & $18(64.3)$ & $26(59.1)$ & $16(55.2)$ & $21(50)$ & $47(23.5)$ & $<0.001$ \\
\hline Mean BP (mmHg, $n=31 / 46 / 33 / 49 / 244)$ & $100(87-117)$ & $104(89-123)$ & $113(87-133)$ & $109(93-123)$ & $110(92-130)$ & $<0.001$ \\
\hline 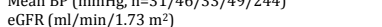 & $102(93-130)$ & $\begin{array}{l}104(89-123) \\
75(64-89)\end{array}$ & $37(31-55)$ & $23(15-29)$ & $6.4(3.7-11.1)$ & $<0.001$ \\
\hline 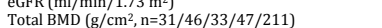 & $1.2(1.1-1.3)$ & $1.2(1.1-1.3)$ & $1.2(1.1-1.3)$ & $\begin{array}{l}23(11.29) \\
1.2(1.0-1.3)\end{array}$ & $\begin{array}{l}6.4(3.7-1.1 .1) \\
1.1(1.0-1.3)\end{array}$ & 0.02 \\
\hline Low physical activity a, $\mathrm{n}(\%)(\mathrm{n}=31 / 45 / 29 / 45 / 225)$ & $1(3)$ & $1(2)$ & $0(0)$ & $7(15)$ & $35(15)$ & $<0.001$ \\
\hline \multicolumn{7}{|l|}{$\begin{array}{l}\text { Nutritional status } \\
\text { (a) }\end{array}$} \\
\hline PEW (SGA>1), n (\%) (n=30/44/33/49/243) & $1(3.3)$ & $1(2.3)$ & $0(0)$ & $8(16)$ & $53(22)$ & $<0.001$ \\
\hline Body mass index $\left(\mathrm{kg} / \mathrm{m}^{2}\right)$ & $24.8(20.3-31.1)$ & $25.4(20.4-31.2)$ & $27.0(22.2-31.7)$ & $25.5(21.0-33.1)$ & $24.6(19.7-30.8)$ & 0.11 \\
\hline Lean body mass index $\left(\mathrm{kg} / \mathrm{m}^{2}, \mathrm{n}=31 / 44 / 31 / 47 / 237\right)$ & $17.7(14.4-20.3)$ & $17.6(14.7-21.3)$ & $18.1(14.9-21.3)$ & $17.9(14.8-21.0)$ & $17.0(13.6-19.9)$ & 0.01 \\
\hline Fat body mass index $\left(\mathrm{kg} / \mathrm{m}^{2}, \mathrm{n}=31 / 44 / 31 / 47 / 237\right)$ & $7.8(4.5-12.3)$ & $7.5(4.6-10.7)$ & $8.2(4.7-12.5)$ & $7.4(4.8-12.3)$ & $7.7(4.2-11.9)$ & 0.90 \\
\hline \multirow{2}{*}{\multicolumn{7}{|c|}{ Markers of metabolism }} \\
\hline & & & & & & \\
\hline Creatinine $(\mu \mathrm{mol} / \mathrm{L})$ & $70(56-81)$ & $90(68-101)$ & $155(121-205)$ & $250(182-341)$ & $691(430-1060)$ & $<0.001$ \\
\hline Triglyceride (mmol/L, $\mathrm{n}=30 / 46 / 32 / 48 / 244)$ & $1.1(0.7-3.1)$ & $1.0(0.7-2.5)$ & $1.6(0.8-3.9)$ & $1.9(0.9-2.9)$ & $1.8(0.9-3.5)$ & $<0.001$ \\
\hline Total Cholesterol (mmol/L, $\mathrm{n}=30 / 46 / 32 / 49 / 245)$ & $4.8(3.6-6.5)$ & $5.1(4.1-6.6)$ & $4.8(3.9-6.0)$ & $5.1(3.7-7.0)$ & $4.7(3.2-6.7)$ & 0.18 \\
\hline HDL Cholesterol (mmol/L, $\mathrm{n}=31 / 46 / 17 / 25 / 243)$ & $1.5(0.9-2.4)$ & $1.4(1.1-2.1)$ & $1.1(0.9-1.8)$ & $1.2(0.8-1.8)$ & $1.2(0.8-1.9)$ & $<0.001$ \\
\hline Calcium (mmol/L, $\mathrm{n}=30 / 46 / 33 / 49 / 241)$ & $2.4(2.1-2.4)$ & $2.3(2.2-2.4)$ & $2.4(2.3-2.6)$ & $2.4(2.2-2.6)$ & $2.5(2.1-2.8)$ & $<0.001$ \\
\hline Phosphate (mmol/L, $\mathrm{n}=30 / 46 / 33 / 49 / 240)$ & $1.0(0.7-1.2)$ & $1.0(0.8-1.2)$ & $1.1(0.7-1.5)$ & $1.3(1.0-1.6)$ & $1.9(1.3-2.7)$ & $<0.001$ \\
\hline Intact-PTH (ng/L, $\mathrm{n}=30 / 45 / 33 / 48 / 244)$ & $34(22-64)$ & $37(27-62)$ & $84(31-142)$ & $105(47-156)$ & $211(47-527)$ & $<0.001$ \\
\hline \multicolumn{7}{|l|}{$\begin{array}{l}\text { Circulating biomarkers } \\
\text { (3)/33/48/244) }\end{array}$} \\
\hline Albumin $(\mathrm{g} / \mathrm{L})$ & $39(37-42)$ & $39(35-43)$ & $38(32-43)$ & $37(29-41)$ & $34(27-40)$ & $<0.001$ \\
\hline Hemoglobin $(\mathrm{g} / \mathrm{L})$ & $142(125-158)$ & $146(131-155)$ & $132(112-149)$ & $124(104-147)$ & $107(90-127)$ & $<0.001$ \\
\hline $\mathrm{hsCRP}(\mathrm{mg} / \mathrm{L})$ & $0.9(0.4-8.1)$ & $1.4(0.4-5.5)$ & $2.8(0.5-10.0)$ & $2.8(0.6-12.3)$ & $4.9(0.7-28.4)$ & $<0.001$ \\
\hline $\mathrm{IGF}-1(\mu \mathrm{g} / \mathrm{mL}, \mathrm{n}=20 / 34 / 23 / 42 / 200)$ & $132(39-248)$ & $111(70-159)$ & $148(61-233)$ & $136(65-233)$ & $186(95-333)$ & $<0.001$ \\
\hline $\mathrm{IL}-6(\mathrm{pg} / \mathrm{mL}, \mathrm{n}=28 / 40 / 13 / 34 / 241)$ & $1.7(0.4-4.7)$ & $2.1(0.8-8.5)$ & $3.3(2.0-6.1)$ & $2.5(1.6-13.8)$ & $6.1(2.3-16.8)$ & $<0.001$ \\
\hline Fibrinogen $(\mathrm{g} / \mathrm{L}, \mathrm{n}=30 / 46 / 31 / 49 / 240)$ & $3.1(2.4-3.9)$ & $2.8(2.3-3.7)$ & $3.2(2.4-4.3)$ & $3.9(2.9-5.9)$ & $4.7(3.4-6.9)$ & $<0.001$ \\
\hline TNF $(\mathrm{pg} / \mathrm{mL}, \mathrm{n}=15 / 25 / 22 / 35 / 228)$ & $3.9(2.5-6.2)$ & $3.7(1.5-9.1)$ & $\begin{array}{l}3.2(2.4-4.3) \\
6.6(4.6-14.2)\end{array}$ & $8.3(5.4-16.6)$ & $11.4(6.3-21.4)$ & $<0.001$ \\
\hline \multirow{2}{*}{\multicolumn{7}{|c|}{$\begin{array}{l}\text { Leucocytes count }\left(10^{9} / \mathrm{L}\right) \\
\text { Medications }\end{array}$}} \\
\hline & & & & & & \\
\hline$\beta$-blockers, $n(\%)(n=31 / 46 / 31 / 49 / 234)$ & $6(19)$ & $9(20)$ & $15(48)$ & $30(61)$ & $153(65)$ & $<0.001$ \\
\hline Ca-blocker, n (\%) (nn31/46/31/49/234) & $2(6)$ & $2(4)$ & $11(35)$ & $24(49)$ & $95(41)$ & $<0.001$ \\
\hline ACEi/ARB, n (\%) (n=31/46/31/49/245) & $3(10)$ & $8(17)$ & $22(71)$ & $39(80)$ & $153(62)$ & $<0.001$ \\
\hline Statins, n (\%) (n=31/46/31/49/245) & $7(23)$ & $4(9)$ & $9(29)$ & $13(27)$ & $70(29)$ & 0.04 \\
\hline \multirow{2}{*}{\multicolumn{7}{|c|}{$\begin{array}{l}\text { Diuretics, } n(\%)(n=31 / 46 / 31 / 49 / 242) \\
\text { Pulmonary function }\end{array}$}} \\
\hline & & & & & & \\
\hline FVC (\% predicted) & $88(69-113)$ & 97 (78-114) & $103(75-117)$ & $90(58-109)$ & $83(59-105)$ & $<0.001$ \\
\hline $\mathrm{FEV}_{1}(\%$ predicted $)$ & $94(78-117)$ & $104(81-123)$ & $103(69-118)$ & $96(49-113)$ & $84(57-106)$ & $<0.001$ \\
\hline PEF (\% predicted) & $87(49-119)$ & $87(56-126)$ & $85(52-122)$ & $75(40-118)$ & $69(37-100)$ & $<0.001$ \\
\hline $\mathrm{FEV}_{1} / \mathrm{FVC}(\%)$ & $86(70-96)$ & $85(74-97)$ & $84(68-93)$ & $84(69-97)$ & $85(68-95)$ & 0.52 \\
\hline Pulse oximetry (\% saturation, $n=30 / 45 / 31 / 46 / 224$ ) & $97(94-99)$ & $97(95-99)$ & $98(95-99)$ & $98(96-99)$ & $98(95-99)$ & 0.007 \\
\hline Normal lung function, $\mathrm{n}(\%)$ & $21(68)$ & $38(83)$ & $27(82)$ & $36(74)$ & $130(53)$ & \\
\hline Obstructive lung function, $\mathrm{n}(\%)$ & $3(10)$ & $3(6)$ & $3(9)$ & $5(10)$ & $28(11)$ & $<0.001$ \\
\hline Restrictive lung function, $\mathrm{n}(\%)$ & $7(22)$ & $5(11)$ & $3(9)$ & $8(16)$ & $87(36)$ & \\
\hline Albuminuria (mg/24 hours) $(\mathrm{n}=26 / 44 / 26 / 40 / 145)$ & $0(0-7)$ & $0(0-51)$ & $308(4-1469)$ & $188(12-1389)$ & $1458(92-6196)$ & $<0.001$ \\
\hline Framingham CVD score (\%) & $14.1(2.3-47.8)$ & $20.2(7.2-52.2)$ & $24.4(2.8-75.3)$ & $20.2(5.9-86.1)$ & $21.8(4.4-55.6)$ & 0.12 \\
\hline
\end{tabular}




\section{Kidney Blood Pressure Research}

\section{Pulmonary function}

The spirometry assessments of forced vital capacity (FVC), forced expiratory volume in the first second $\left(\mathrm{FEV}_{1}\right)$ and peak expiratory flow (PEF) were obtained using Spirolab (Medical International Research, Rome, Italy) with flow accuracy $\pm 5 \%$ and volume accuracy $\pm 3 \%$ at the Department of Clinical Physiology, Karolinska University Hospital, Karolinska Institutet, Campus Flemingsberg, Stockholm. Predicted normal values were calculated using the formulas by Crapo et al. [16] and expressed as $\% \mathrm{FEV}_{1}, \% \mathrm{FVC}$ and $\% \mathrm{PEF}$. At least three reproducible tests were carried out for each measurement and the highest was recorded. Pulse oximetry yielding oxygen saturation $\left(\mathrm{SpO}_{2}\right)$ was performed with a Datex-Engström Finger Sensor (DatexEngström Division, Instrumentarium Division, Finland) measuring red and infrared light absorption with accuracy $\pm 2 \%$ in the $\mathrm{SpO}_{2}$ interval $80-100 \%$. Obstructive impairment was defined as $\mathrm{FEV}_{1} / \mathrm{FVC}<0.70$, and restrictive impairment as the $\mathrm{FEV}_{1} / \mathrm{FVC} \geq 0.70$, and $\% \mathrm{FVC}<80$ [17].

Relatively few $(n=24)$ of the patients had pre-existing pulmonary disease diagnoses at baseline. Based on ICD-10 codes (10th revision of the International Statistical Classification of Diseases and Related Health Problems) previously recorded diagnoses included: upper respiratory infection (J069-J101; n=3); pneumonia (J180-J189; $\mathrm{n}=5$ ); bronchitis (J209; $\mathrm{n}=2)$; chronic obstructive pulmonary disease, COPD (J441-J449; n=10); asthma (J459; n=2); interstitial pulmonary disease (J841; $\mathrm{n}=1$ ); and pneumothorax (J939; $n=1)$. None of these patients had signs of overt clinical infection at the time of investigation.

\section{Biochemical analysis}

Blood samples were collected at baseline evaluation after overnight fasting. The plasma was separated within 30 minutes, and samples were kept frozen at $-70^{\circ} \mathrm{C}$ if not analyzed immediately. Analyses of plasma high-sensitivity C-reactive protein (hsCRP; coefficient of variation, CV, 5\%), cholesterol, triglycerides, HDLcholesterol, calcium, phosphate, hemoglobin, creatinine, and albumin (CV 3-4\%) were performed at the Clinical Laboratory of Karolinska University Hospital, Campus Flemingsberg, Stockholm. Interleukin-6, IL-6 (CV 4\%), insulin-like growth factor-1, IGF-1 (CV 4.3\%) and tumor necrosis factor (TNF) were measured on an Immulite 1000 Automatic Analyzer (Siemens Healthcare, Diagnostics Products Ltd, Los Angeles, CA, USA) at the laboratory of Department of Renal Medicine using assays manufactured for this analyzer and according to the manufacturer's instructions. Presence of CVD was defined as a clinical history or signs of ischemic cardiac disease, and/or presence of peripheral vascular disease, cerebrovascular disease/presence of heart failure, and arrhythmia. Blood pressure is presented as mean blood pressure defined as [diastolic pressure + (systolic pressure - diastolic pressure) / 3] .

\section{Nutritional assessment}

According to the subjective global assessment (SGA) score, patients were classified as well nourished (SGA score $=1$ ) or as having mild ( $S G A=2)$, moderate $(S G A=3)$ or severe $(S G A=4)$ malnutrition (i.e., proteinenergy wasting, PEW) [18]. For simplicity, the patients were combined in two groups; malnourished $(\mathrm{SGA} \geq 2)$ and well nourished $(\mathrm{SGA}=1)$. Handgrip strength $(\mathrm{HGS})$ was evaluated in the non-dominant arm using the Harpenden dynamometer (Yamar, Jackson, MI, USA) and repeated three times, and the greatest value was recorded. The individual values for HGS were expressed as percentage of healthy individuals (\%HGS), adjusting for the gender, when included in the statistical analyses. Body mass index was calculated as weight in kilograms divided by the square of height in meters. Lean body mass and fat mass were calculated by anthropometry with measurements of biceps, triceps, subscapular and supra-iliac skinfold thickness using the Durnin and Womerslesy caliper method [19], and by equations proposed by Siri [20]. Lean body mass index (LBMI) and fat body mass index (FBMI) were calculated according to the method of Kyle et al. [21] and expressed as $\mathrm{kg} / \mathrm{m}^{2}$. Physical activity was reported by each individual in a questionnaire allowing choices between four domains: 1) exercise frequently, 2) normal activity, 3) low activity, and 4) bedridden or wheelchair bound.

\section{Statistical analysis}

Data are expressed as median (10th to 90th percentile) or percentage or sub hazard ratios, as appropriate. Statistical significance was set at the level of $\mathrm{P}<0.05$. Comparisons between two groups were assessed with the non-parametric Wilcoxon test for continuous variables and Fischer's exact test for 


\section{Kidney Blood Pressure Research}

Kidney Blood Press Res 2018;43:522-535

\begin{tabular}{l|l}
\hline DOI: 10.1159/000488699 & (C) 2018 The Author(s). Published by S. Karger AG, Basel
\end{tabular}

Published onlıne: 6 April, 2018

www.karger.com/kbr

Mukai et al.: Pulmonary Dysfunction and Survival in CKD

nominal variables. Differences between more than two groups were analyzed using the non-parametric ANOVA Kruskal-Wallis test followed by the Dunn's test.

The patients were followed from the inclusion date until renal transplantation, death, completion of 60 months of follow-up, or until Dec 31, 2015. The cause of death was established through death certificate issued by the attending physician. We applied Framingham CVD risk score [22] in order to consider the following traditional risk factors: age, gender, diabetes, systolic blood pressure, anti-hypertensive medication, total cholesterol, HDL-cholesterol and smoking. Survival during follow-up was analyzed by the competing-risk regression model and the cumulative incidence curve [23]. We used Fine \& Gray models and these were adjusted for confounders [24]. The sub-hazard ratios (sHR) for one standard deviation (1$\mathrm{SD}$ ) higher level of $\% \mathrm{FEV}_{1}$ and $\% \mathrm{FVC}$ and sHR for high tertile of $\% \mathrm{FEV}_{1}$ and $\% \mathrm{FVC}$ were calculated with competing-risk regression models with transplantation as a competing risk. Framingham CVD risk score, BMI, history of CVD, albumin, PEW, hsCRP and albuminuria were considered as confounding factors. Albuminuria was investigated by 24 hours urine collection. We used cutoff of urinary albumin excretion $\geq 30 \mathrm{mg} /$ day as a clinically meaningful definition of albuminuria. Goodness of fit of the models was also evaluated with particular attention to the underlying proportionality assumption; no violations of the assumption were found in our analyses. We used logistic regression analysis to examine factors associated with the prevalence of CVD. In addition to gender, diabetes, and smoking, one standard deviation (1-SD) increments of age, albumin, hsCRP, eGFR, $\% \mathrm{FEV}_{1}$ and $\% \mathrm{FVC}$ s were considered in the multivariable logistic model. All statistical analyses were performed using statistical software SAS version 9.4 (SAS Campus Drive, Cary, NC, USA).

\section{Results}

\section{Clinical characteristics}

Clinical and biochemical characteristics of all individuals ( $n=404$; GFR categories 1-5), divided according to whether they had normal $(n=252 ; 63 \%)$, obstructive $(n=42 ; 10 \%)$ or restrictive $(n=110 ; 27 \%)$ lung function at baseline, are presented in Table 2 . While age and sex were similar among the three groups, patients with restrictive lung function had more often comorbidities (diabetes mellitus, DM, CVD, and PEW), higher levels of inflammation biomarkers (hsCRP and IL-6), lower physical activity, lower HGS, and more frequent usage of $\beta$-blockers and statins.

Patients with restrictive lung function had low $\% \mathrm{FVC}$ (median 69\%) and $\% \mathrm{FEV}_{1}$ (median $73 \%)$; however, the decline in $\% \mathrm{FVC}$ was more pronounced than that of $\% \mathrm{FEV}_{1}$, resulting in a high ratio of $\mathrm{FEV}_{1} / \mathrm{FVC}$ (median 88\%). In those with obstructive lung function, $\% \mathrm{FEV}_{1}$ was reduced to median $63 \%$ while $\% \mathrm{FVC}$ was less altered (median $82 \%$ ), and consequently the $\mathrm{FEV}_{1} / \mathrm{FVC}$ ratio was markedly reduced to median $65 \%$.

Patients with more advanced GFR categories had more often comorbidities (DM, CVD and PEW), lower HGS and were more inflamed than those in other GFR categories, and they had lower $\% \mathrm{FEV}_{1}, \% \mathrm{FVC}$ and \%PEF while FEV1/FVC was similar across GFR categories (Table 1). Obstructive and especially restrictive lung dysfunction was more common among those with advanced CKD (GFR category 4 and 5). Univariate associations between lung function indices and other parameters are given in Table 3. DM patients $(n=114)$ had lower $\% \mathrm{FVC}$ and $\% \mathrm{FEV}_{1}$, and more often comorbid conditions than non-DM patients. Patients with CVD $(n=111)$ had lower $\% \mathrm{FVC}$ and $\% \mathrm{FEV}_{1}$, and were older, and had more often comorbid conditions, inflammation and PEW than patients without CVD $(\mathrm{n}=293)$. CVD was predicted in multivariate logistic regression by 1-SD increments of \%FVC OR, 95\% CI(0.59 (0.41-0.84) $\mathrm{p}=0.003)$ and $\% \mathrm{FEV}_{1} \mathrm{OR}, 95 \% \mathrm{CI}(0.70(0.51-0.96) \mathrm{p}=0.03)$ respectively, after adjusting for age, gender, DM and smoking and 1-SD increments of albumin, hsCRP, and eGFR. Patients with PEW (SGA $>1 ; n=63$ ) had lower $\% \mathrm{FVC}$ and $\% \mathrm{FEV}_{1}$, and had more often comorbid conditions and inflammation than well-nourished patients $(\mathrm{n}=336)$ (data not shown). 


\section{Kidney \\ Blood Pressure Research}

Table 2. Clinical and biochemical characteristics of 404 individuals divided according to lung function. Continuous variables are presented as median (10 - 90 percentile). Categorical variables are presented as number (n)/percentage (\%). Abbreviations: Mean BP, mean blood pressure; GFR, glomerular filtration rate; Total BMD, Total bone mineral density; PEW, protein-energy wasting; SGA, Subjective global nutritional assessment; HDL, high-density lipoprotein; intact-PTH, intact parathyroid hormone; hsCRP, high-sensitivity C-reactive protein; IGF-1, insulin-like growth factor-1; IL-6, interleukin-6; TNF, tumor necrosis factor; ACEi, angiotensin-converting enzyme; $\mathrm{ARB}$, angiotensin 2 receptor blocker; FVC, forced vital capacity; $\mathrm{FEV}_{1}$, forced expiratory volume in the first second; PEF, peak expiratory flow. a Low physical activity or bed or wheelchair bound (according to questionnaire where patient reported one of four domains: 1) exercise frequently, 2) normal activity, 3) low activity, or 4) bedridden or wheelchair bound); b \% HGS, Handgrip strength as percentage of values for CKD 1 and 2. Obstructive impairment: FEV1/FVC $<0.70$. Restrictive impairment: FEV1/FVC $\geq 0.70$ and $\%$ FVC $<80$

\begin{tabular}{|c|c|c|c|c|}
\hline Demography and clinical characteristics & $\begin{array}{c}\text { Normal } \\
(\mathrm{n}=252)\end{array}$ & $\begin{array}{c}\text { Obstructive } \\
(\mathrm{n}=42)\end{array}$ & $\begin{array}{c}\text { Restrictive } \\
(\mathrm{n}=110)\end{array}$ & P value \\
\hline Age (years) & $57(36-71)$ & $63(32-72)$ & $59(37-71)$ & 0.14 \\
\hline Males, n (\%) & $159(63)$ & $28(67)$ & $75(68)$ & 0.62 \\
\hline Diabetes mellitus, n (\%) & $52(21 \%)$ & $11(26 \%)$ & $51(46 \%)$ & $<0.001$ \\
\hline Cardiovascular disease, n (\%) & $45(18 \%)$ & $13(31 \%)$ & $53(48 \%)$ & $<0.001$ \\
\hline Smoker, n (\%) (n=219/37/87) & $85(39)$ & $11(30)$ & $32(37)$ & 0.56 \\
\hline Mean BP (mmHg, $n=252 / 41 / 110)$ & $109(91-125)$ & $106(90-137)$ & $107(90-130)$ & 0.99 \\
\hline Low physical activity a, n (\%) (n=234/36/105) & $14(6)$ & $6(17)$ & $24(23)$ & $<0.001$ \\
\hline Framingham CVD risk score $(\%)(n=252 / 42 / 110)$ & $17.8(3.8-56.3)$ & $31.3(4.5-58.3)$ & $24.9(5.3-61.0)$ & 0.01 \\
\hline Urine albumin $\geq 30 \mathrm{mg} /$ day, $\mathrm{n}(\%) \quad(\mathrm{n}=190 / 26 / 65)$ & $121(64)$ & $19(73)$ & $54(69)$ & 0.009 \\
\hline $\mathrm{eGFR}\left(\mathrm{ml} / \mathrm{min} / 1.73 \mathrm{~m}^{2}\right)$ & $13.5(4.6-88.9)$ & $9.8(4.4-76.4)$ & $6.9(3.8-68.1)$ & $<0.001$ \\
\hline \multicolumn{5}{|l|}{ Nutritional status } \\
\hline PEW (SGA>1), n (\%) (n=250/40/109) & $17(7 \%)$ & $12(30 \%)$ & $34(31 \%)$ & $<0.001$ \\
\hline Body mass index, $\left(\mathrm{kg} / \mathrm{m}^{2}\right)$ & $25.2(20.2-30.8)$ & $22.9(18-28.6)$ & $24.7(20.3-32.4)$ & 0.004 \\
\hline Lean body mass index, $\left(\mathrm{kg} / \mathrm{m}^{2}, \mathrm{n}=249 / 40 / 101\right)$ & $17.4(14.6-20.5)$ & $16.3(13.2-19.7)$ & $17.3(13.6-20.6)$ & 0.03 \\
\hline Fat body mass index, $\left(\mathrm{kg} / \mathrm{m}^{2}, \mathrm{n}=249 / 40 / 101\right)$ & $7.9(4.6-11.7)$ & $6.8(3.9-10.8)$ & $7.5(4.1-12.6)$ & 0.06 \\
\hline$\% \mathrm{HGS}^{\mathrm{b}}(\%, \mathrm{n}=251 / 41 / 107)$ & $100(70-122)$ & $80(50-106)$ & $85(55-122)$ & $<0.001$ \\
\hline Total BMD (g/cm², n=238/37/93) & $1.17(1.02-1.31)$ & $1.14(0.98-1.29)$ & $1.15(1.03-1.33)$ & 0.30 \\
\hline \multicolumn{5}{|l|}{ Markers of metabolism and nutrition } \\
\hline Hemoglobin (g/L) & $123(94-148)$ & $116(86-146)$ & $109(93-138)$ & $<0.001$ \\
\hline Albumin (g/L) & $37(30-42)$ & $35(27-41)$ & $34(24-40)$ & $<0.001$ \\
\hline IGF-1 ( $\mu \mathrm{g} / \mathrm{mL}, \mathrm{n}=204 / 29 / 86)$ & $155(81-307)$ & $170(53-234)$ & $158(65-289)$ & 0.62 \\
\hline Triglyceride (mmol/L, n=249/42/109) & $1.6(0.7-3.3)$ & $1.7(0.9-3.3)$ & $1.7(0.9-3.3)$ & 0.57 \\
\hline Total cholesterol (mmol/L, $\mathrm{n}=251 / 42 / 109$ ) & $5.0(3.6-6.6)$ & $5.1(3.7-7.0)$ & $4.4(3.1-6.6)$ & $<0.001$ \\
\hline HDL cholesterol (mmol/L, n=216/39/107) & $1.3(0.9-2.1)$ & $1.2(0.7-2.1)$ & $1.2(0.8-2.0)$ & 0.22 \\
\hline Calcium $(\mathrm{mmol} / \mathrm{L},=251 / 40 / 108)$ & $2.4(2.2-2.8)$ & $2.5(2.1-2.7)$ & $2.4(2.1-2.7)$ & 0.22 \\
\hline Phosphate (mmol/L, n=250/40/108) & $1.4(0.9-2.5)$ & $1.5(0.9-2.6)$ & $1.8(0.9-2.7)$ & $<0.001$ \\
\hline Intact-PTH (ng/L, n=248/42/110) & $103(30-398)$ & $93(30-482)$ & $197(33-469)$ & $<0.001$ \\
\hline \multicolumn{5}{|l|}{ Biomarkers of inflammation } \\
\hline hsCRP (mg/L) & $2.5(0.5-14.0)$ & $4.3(0.8-52.3)$ & $7.7(1.1-30.8)$ & $<0.001$ \\
\hline IL-6 (pg/mL, n=214/37/105) & $3.3(1.2-10.1)$ & $8.1(2.2-18.7)$ & $6.3(2.3-21.7)$ & $<0.001$ \\
\hline Fibrinogen $(\mathrm{g} / \mathrm{L}, \mathrm{n}=247 / 41 / 108)$ & $3.7(2.6-5.9)$ & $4.1(2.8-6.4)$ & $5.0(3.1-6.9)$ & $<0.001$ \\
\hline TNF (pg/mL, n=194/35/96) & $8.9(4.1-16.7)$ & $10.3(3.9-27.4)$ & $12.8(6.5-21.4)$ & $<0.001$ \\
\hline Leucocytes count $\left(10^{9} / \mathrm{L}\right)$ & $6.8(4.7-9.6)$ & $7.4(5.4-11.3)$ & $8.3(5.1-12.4)$ & $<0.001$ \\
\hline \multicolumn{5}{|l|}{ Medications } \\
\hline$\beta$-blocker, n (\%) (n=244/40/107) & $122(50)$ & $22(55)$ & $69(64)$ & 0.04 \\
\hline Ca-blocker, n (\%) (n=244/40/107) & $80(33)$ & $11(28)$ & $43(40)$ & 0.26 \\
\hline ACEi/ARB, n (\%) (n=251/41/110) & 149 (59) & $18(44)$ & $58(53)$ & 0.13 \\
\hline Statins therapy, n (\%) $(n=251 / 41 / 110)$ & $56(22)$ & $5(12)$ & $42(38)$ & $<0.001$ \\
\hline Diuretics, $n(\%)(n=249 / 41 / 109)$ & $148(59)$ & $29(71)$ & $88(81)$ & $<0.001$ \\
\hline \multicolumn{5}{|l|}{ Pulmonary function } \\
\hline FVC (\% predicted) & $94(83-112)$ & $82(59-118)$ & $69(51-78)$ & $<0.001$ \\
\hline $\mathrm{FEV}_{1}(\%$ predicted $)$ & $98(83-118)$ & $63(46-96)$ & $73(54-86)$ & $<0.001$ \\
\hline PEF (\% predicted) & $81(49-118)$ & $39(23-85)$ & $68(40-97)$ & $<0.001$ \\
\hline $\mathrm{FEV}_{1} / \mathrm{FVC}(\%)$ & $85(75-95)$ & $65(52-69)$ & $88(76-96)$ & $<0.001$ \\
\hline Pulse oxymetry ( $\%$ saturation, $n=239 / 35 / 102$ ) & $98(95-99)$ & $98(95-99)$ & $98(94-99)$ & 0.45 \\
\hline
\end{tabular}




\section{Kidney \\ Blood Pressure Research}

Mukai et al.: Pulmonary Dysfunction and Survival in CKD

Table 3. Univariate associations expressed as rho correlations of $\% \mathrm{FEV}_{1}$ and $\% \mathrm{FVC}$ with other variables at baseline in 404 GFR categories G1 - 5 individuals. Abbreviations: $\% \mathrm{FEV}_{1}$, percentage of predicted forced expiratory volume in 1 second value; \%FVC, percentage of predicted forced vital capacity value; eGFR, estimated glomerular filtration rate; PEW, protein-energy wasting; SGA, Subjective global nutritional assessment score; \%HGS, Handgrip strength as percentage of values for CKD 1 and 2; hsCRP, high-sensitivity C-reactive protein; IL-6, interleukin-6

\begin{tabular}{lcccc}
\hline Characteristics & \multicolumn{3}{c}{$\% \mathrm{FEV}_{1}$} & \multicolumn{2}{c}{$\% \mathrm{FVC}$} \\
& rho & p value & rho & p value \\
\hline Age (years) & -0.04 & 0.48 & -0.08 & 0.096 \\
Males (\%) & 0.01 & 0.78 & -0.06 & 0.23 \\
Diabetes mellitus (present) & -0.22 & $<0.001$ & -0.25 & $<0.001$ \\
Cardiovascular disease (present) & -0.29 & $<0.001$ & -0.34 & $<0.001$ \\
Smoking & 0.04 & 0.50 & 0.01 & 0.79 \\
Mean blood pressure (mmHg) & -0.08 & 0.12 & -0.02 & 0.66 \\
eGFR (ml/min/1.73 $\mathrm{m}^{2}$ ) & 0.34 & $<0.001$ & 0.28 & $<0.001$ \\
PEW (SGA>1) (\%) & -0.31 & $<0.001$ & -0.31 & $<0.001$ \\
Body mass index $\left(\mathrm{kg} / \mathrm{m}^{2}\right)$ & 0.07 & 0.15 & 0.01 & 0.79 \\
Lean body mass index $\left(\mathrm{kg} / \mathrm{m}^{2}\right)$ & 0.14 & 0.007 & 0.07 & 0.19 \\
Fat body mass index $\left(\mathrm{kg} / \mathrm{m}^{2}\right)$ & -0.004 & 0.94 & -0.02 & 0.64 \\
\%HGS (\%) & 0.31 & $<0.001$ & 0.32 & $<0.001$ \\
Calcium (mmol/L) & -0.06 & 0.23 & -0.02 & 0.72 \\
Phosphate (mmol/L) & -0.30 & $<0.001$ & -0.28 & $<0.001$ \\
hsCRP (mg/L) & -0.41 & $<0.001$ & -0.36 & $<0.001$ \\
IL-6 (pg/mL) & -0.45 & $<0.001$ & -0.40 & $<0.001$ \\
Albuminuria (mg/24 hours) & -0.34 & $<0.001$ & -0.27 & $<0.001$ \\
Framingham CVD score (\%) & -0.13 & 0.008 & -0.18 & $<0.001$ \\
\hline
\end{tabular}

The proportion of individuals with obstructive and especially restrictive lung function increased with increasing number of comorbid conditions (CVD, inflammation and PEW (Fig. 1). The prevalence of restrictive lung function increased from $13 \%$ in patients with none of these factors to $64 \%$ when three of them were present.

Fig. 2 shows $\% \mathrm{FEV}_{1}$ and $\% \mathrm{FVC}$ at baseline and follow-up in patients who had normal lung function, or obstructive or restrictive lung function at baseline in total 404 patients. As expected patients with restrictive lung impairment at baseline had lower $\% \mathrm{FVC}$ and $\% \mathrm{FEV}_{1}$ than patients with normal lung function.

Among the $\mathrm{G}-5$ patients $(\mathrm{n}=245)$ who were re-assessed after 1 year $(\mathrm{n}=130)$ and 2 years $(\mathrm{n}=65)$, both $\% \mathrm{FEV}_{1}$ and \%FVC remained essentially unchanged over time, independent of whether they had obstructive or restrictive lung function at baseline (data not shown). Renal replacement treatment did not appear to impact on lung function indices during follow up in G-5 patients; thus $\% \mathrm{FEV}_{1}$ and \%FVC levels were essentially similar independent of whether patients underwent conservative, hemodialysis (HD) or peritoneal dialysis (PD) treatment (data not shown).

\section{Association between lung function and mortality}

During follow-up over 5 years, the overall mortality rate was $24 \%(n=95)$ among the 404 individuals. As almost half of the G-5 individuals underwent renal transplantation ( $\mathrm{n}=$ 112) during the follow-up period, competing-risk regression models with transplantation as a competing risk were used for survival analyses.

Among all 404 GFR categories 1-5 individuals, 1-SD higher $\% \mathrm{FEV}_{1}$ and 1-SD higher \%FVC associated with lower mortality risk with crude sHR $=0.49$ (95\%CI 0.27 to 0.88$)$ and crude sHR $=0.56(95 \%$ CI 0.32 to 0.98 ) respectively. After adjusting for tertiles of Framingham CVD score (representing age, gender, DM, systolic blood pressure, use of anti-hypertensive medication, total cholesterol, HDL-cholesterol and smoking), the survival benefits associated with 1-SD higher \%FEV and 1-SD higher \%FVC remained significant, sHR 0.62 (95\% CI 0.48 to $0.79 ; \mathrm{p}=0.001$ ) and sHR 0.63 (95\% CI 0.47 to $0.85 ; \mathrm{p}=0.003)$ respectively.

The highest tertiles (as compared to the other tertiles) of $\% \mathrm{FEV}_{1}$ and $\% \mathrm{FVC}$ respectively associated with lower all-cause mortality after adjustments for tertiles of Framingham CVD score (representing age, gender, DM, systolic blood pressure, use of anti-hypertensive 


\section{Kidney Blood Pressure Research}

Fig. 1. Prevalence of restrictive and obstructive lung dysfunction and normal lung function among 404 individuals with GFR categories G-1 to G-5 in relation to number of concomitantly present comorbid conditions, PEW, inflammation and CVD. Abbreviations: Obstructive, Obstructive lung function; Restrictive, Restrictive lung function.

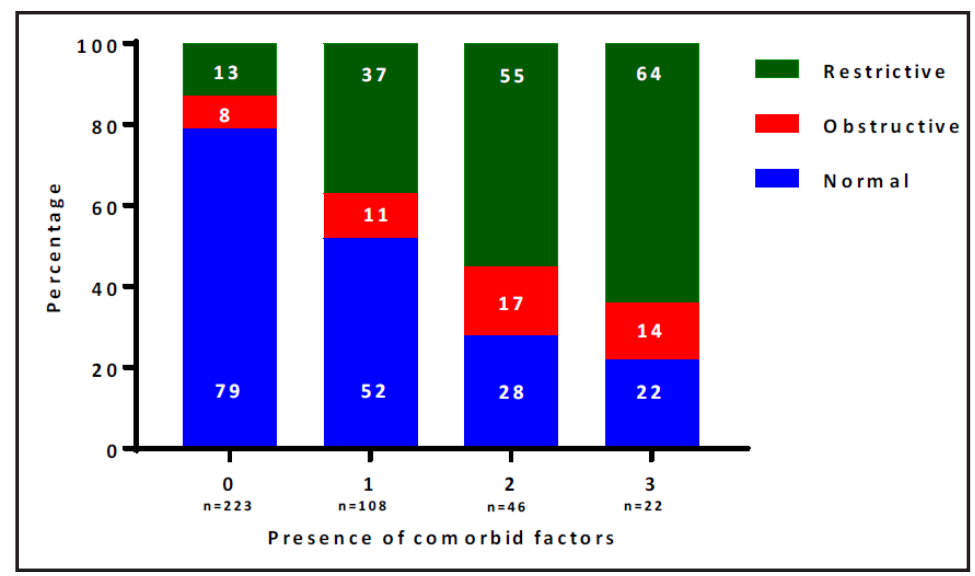

Fig. 2. Lung function indices, $\% \mathrm{FEV} 1$ and \%FVC, in 404 patients with GFR categories G-1 to G-5 who had normal, obstructive or restrictive lung function at baseline $(\mathrm{n}=404)$, and results at follow up after 1 year $(n=192)$ and 2 years $(\mathrm{n}=118)$ respectively. Abbreviations: \%FEV1, Forced expiratory volume in the first second expressed as percentage of predicted normal values; \%FVC, Forced vital capacity expressed as percentage of predicted normal values; Base, baseline; $1 \mathrm{Y}, 1$ year; $2 \mathrm{Y}, 2$ years.

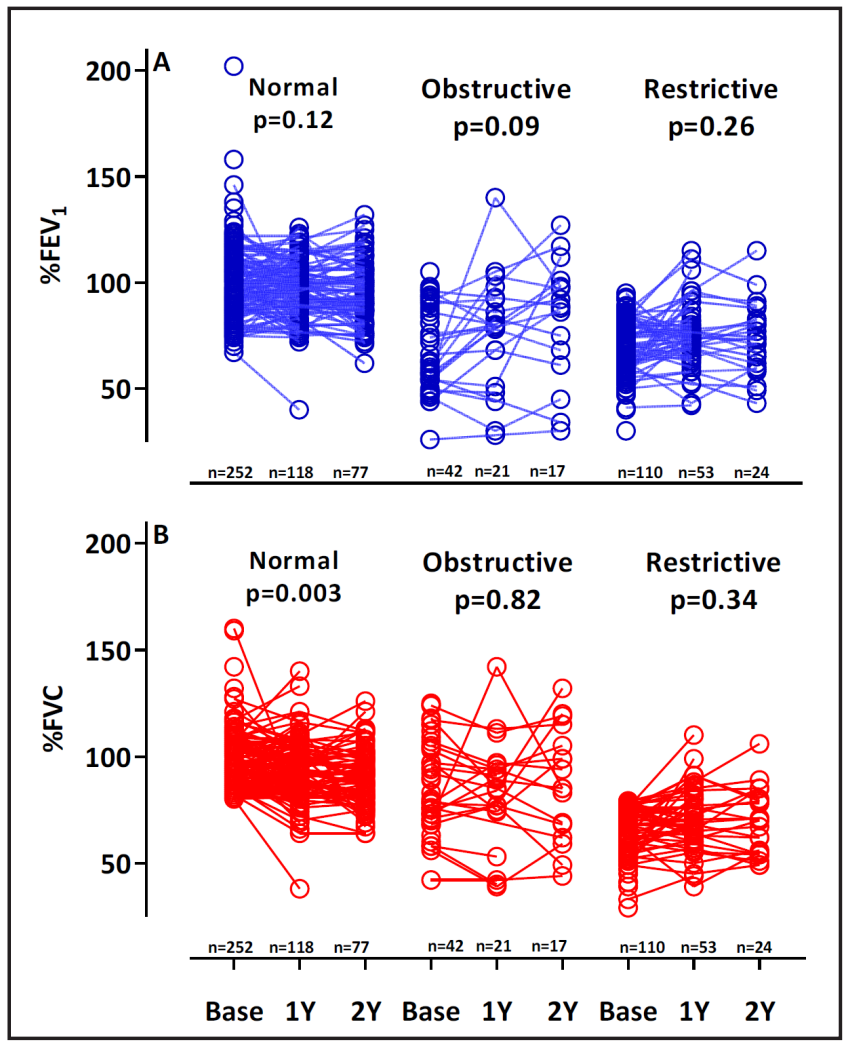

medication, total cholesterol, HDL-cholesterol and smoking), presence of CVD and PEW, and albumin, BMI, hsCRP, and albuminuria, sHR of 0.49 (95\% CI, 0.27 to $0.88, \mathrm{p}=0.01$ ) and sHR of $0.56(95 \% \mathrm{CI}, 0.32$ to $0.98, \mathrm{p}=0.04)$ respectively (Fig. $3 \mathrm{~A}$ and $3 \mathrm{~B})$.

After applying the same adjustments, the highest tertile (as compared to the other tertiles) of $\% \mathrm{FEV}_{1}$ associated with lower CVD mortality with sHR of 0.16 (95\% CI, 0.04 to $0.69, \mathrm{p}=0.01$ ) (Fig. 3C). The association of the highest tertile of \%FVC with CVD mortality was not significant; data not shown).

Restrictive lung dysfunction associated with increased mortality risk (sHR of 1.80, $95 \% \mathrm{CI}, 1.04$ to $3.13, \mathrm{p}=0.03$ ) while the association with obstructive lung impairment was not significant after adjusting for Framingham CVD risk score (representing age, gender, DM, smoking, total cholesterol, HDL-cholesterol and anti-hypertensive treatment); presence of CVD, PEW and albuminuria; and levels of BMI, plasma albumin and hsCRP, as well as \%HGS, (Fig. 3D). 


\section{Kidney Blood Pressure Research}
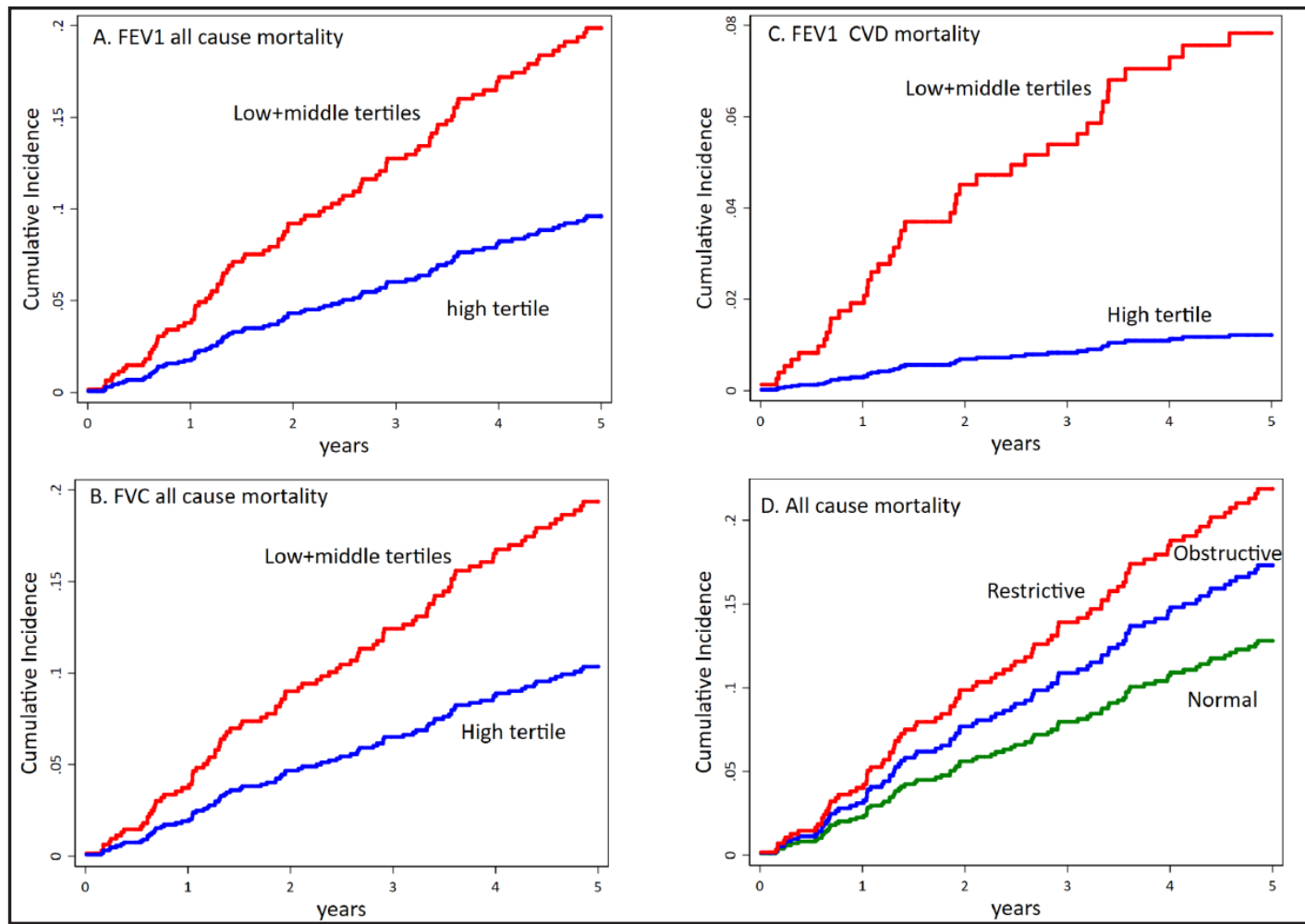

Fig. 3. Cumulative incidence curves of 5 -year survival in 404 patients with GFR categories G-1 to G-5 in relation to baseline values of \%FEV1, \%FVC, \%FEV1, and baseline presence of normal vs obstructive or restrictive lung function. Associations were expressed as sHR(95\%CI) following adjustments for: Framingham CVD risk score (representing age, gender, DM, smoking, total cholesterol, HDL-cholesterol, and anti-hypertensive treatment), presence of CVD, PEW and albuminuria, and BMI and plasma albumin and hsCRPlevels. A:The highest tertile $(n=140)$ as compared to low + middle tertiles $(n=264)$ of \%FEV1associated with lower allcause mortality with sHRof 0.49 (95\% CI, 0.27 to 0.88$)$. B: The highest tertile( $n=139)$ as compared to low + middle tertiles $(\mathrm{n}=265)$ of \%FVC associated with lower all-cause mortality with sHRof 0.56 (95\% CI, 0.32 to 0.98). C: The highest tertile( $n=140)$ as compared to low + middle tertiles( $n=264)$ of $\%$ FEV1associated with lower CVD mortality with sHRof 0.16 (95\% CI, 0.04 to 0.69). D: Restrictive lung function associated with higher all-cause mortality risk with sHRof 1.80 (95\% CI 1.04 to 3.13, p=0.03). The association of obstructive lung impairment with mortality was not significant.

\section{Discussion}

Although lung dysfunction is a known complication in CKD, its prevalence, characteristics and clinical implications in relation to GFR are largely unexplored. In this cohort study of 404 clinically stable individuals, representing all GFR categories, and few (6\%) had pre-existing pulmonary disease diagnoses, lung dysfunction was a strong independent predictor of worse 5 -year survival. The present study is the first longitudinal study exploring associations between pulmonary function and mortality over the spectrum of all GFR categories.

The negative impact of lung dysfunction on clinical outcome appeared to be mainly due to restrictive lung dysfunction that was a common complication among those with advanced CKD, especially in those with comorbidities. In the Swedish population, the prevalence of chronic obstructive pulmonary disease (COPD) was reported to range between $10 \%$ and $16 \%$ among selected-middle aged participants; however, the role of impaired GFR was not investigated $[25,26]$. In the present study, while the prevalence of obstructive lung function 


\section{Kidney Blood Pressure Research}

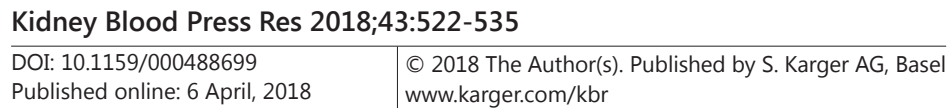

Mukai et al.: Pulmonary Dysfunction and Survival in CKD

increased slightly across GFR categories 1-5, from 6\% in G-2 to $11 \%$ in G-5, these figures are lower than in the general Swedish population. Whether this discrepancy reflects selection bias for example due to putative survival benefit of CKD patients with normal lung function (who lived long enough to be included in our study), or differences in methodology and criteria for lung dysfunction is unclear. On the other hand, the prevalence of restrictive lung function was markedly higher as GFR declined in our individuals, from $9 \%$ in G-3 to $36 \%$ in G-5 individuals, and it was as high as $64 \%$ in individuals $(n=22)$ with concomitant presence of PEW, inflammation and CVD (Fig. 1). The prevalence of restrictive lung function in our patients is higher than values reported in a Swedish general population sample, aged 21-86 years, where the prevalence of a restrictive spirometric pattern was $9-11 \%$ when based on pre-bronchodilator values and 7\% when based on post-bronchodilator values; however, the role of GFR was not investigated [27].

In the general population, reduced $\% \mathrm{FEV}_{1}$ and $\% \mathrm{FVC}$ are associated with presence of CVD and increased all-cause mortality risk $[8,9]$ and, in middle-aged individuals as well as in patients with COPD, lung dysfunction associates with CVD and increased CVD-related mortality $[28,29]$. However, there are few previous studies on associations between pulmonary function and all-cause and CVD-mortality across the entire spectrum of GFR categories. In the present study, using competing-risks regression analysis, and adjusting for Framingham CVD score (representing age, gender, DM, systolic blood pressure, use of anti-hypertensive medication, total cholesterol, HDL-cholesterol, and smoking), presence of CVD, PEW, and albuminuria, and levels of BMI, albumin, hsCRP and albuminuria, the highest tertiles of $\% \mathrm{FEV}_{1}$ and $\% \mathrm{FVC}$ associated with lower all-cause mortality and the highest tertile of $\% \mathrm{FEV}_{1}$ associated also with lower CVD mortality. In accordance, a previous study reported that a low \%FVC was associated with high mortality in CKD 5 patients [10] while another study failed to show that low $\% \mathrm{FEV}_{1}$ was associated with mortality in dialysis patients [11].

Although it is well recognized that smoking impairs lung function and associates with cardiovascular events [30-33], impaired lung function associates with all-cause and cardiovascular mortality, independent of smoking $[8,34,35]$. The present study confirms that impaired lung function in CKD is associated with all-cause and CVD mortality, independent of smoking. Among possible explanations, the loss of renal function in CKD results in fluid overload and metabolic and endocrine abnormalities that may promote restrictive lung impairment in CKD [6]. Our finding that lower muscle strength (\%HGS) associates with impaired lung function is in line with previous observations that decreased respiratory muscle strength may lead to decreased vital capacity in CKD patients [36].

Previous studies reported an inverse association between inflammation and lung function indices FVC and $\mathrm{FEV}_{1}$ [37-39]. In the present study, lung function indices were inversely associated with inflammation (data not shown). Since a longitudinal association between lower lung function and inflammation has been reported [40], it is possible that a reduced lung volume in our individuals may be linked to increased systemic inflammation. A previous study reported associations of inflammation with obstructive and restrictive lung disease [41]. Impaired lung function associates with inflammation and increased cardiovascular risk [42]. Inflammation is a strong predictor of atherosclerosis and cardiovascular events in the general population [43-47]. The mechanisms for pathogenesis of COPD, which may lead to CVD, are thought to involve inflammation, neurohumoral activation, cachexia, and skeletal muscle dysfunction [48-51]. In the present study, presence of CVD was independently associated with $\% \mathrm{FEV}_{1}$ or $\% \mathrm{FVC}$ even after adjusting for age, gender, inflammation, albumin, smoking, diabetes and eGFR (data not shown).

Protein-energy wasting (PEW) and inflammation are common (30-50\%) interlinked conditions in patients with advanced CKD, and presence of chronic low-grade inflammation is thought to play a central role in the pathophysiology of a range of complications in uremia $[15,52]$. In the present study, lung function indices, $\% \mathrm{FVC}$ and $\% \mathrm{FEV}_{1}$, were significantly lower in individuals presenting with PEW and inflammation. Concomitant presence of more comorbid factors (PEW, inflammation and CVD) associated with progressively higher 


\section{Kidney Blood Pressure Research}

prevalence of restrictive lung function (Fig. 1). On the other hand, measurements repeated in G5 patients after 1 year and 2 years showed that $\% \mathrm{FEV}_{1}$ and $\% \mathrm{FVC}$ remained essentially unchanged during follow up, independent of uremia treatment (conservative, hemodialysis or peritoneal dialysis). Thus it is likely that abnormalities of uremia including inflammation rather than the type of uremia treatment may contribute to impaired lung function in CKD. Our findings of strong associations of lung function with inflammation, PEW, and CVD and with clinical outcomes across GFR categories suggest that also lung status, a previously often overlooked factor, should be considered in risk assessments in these individuals. Furthermore, in the Atherosclerosis Risk in Communities (ARIC) Study, reduced lung function, particularly lower percent-predicted FVC, was found to be independently associated with CKD progression [53].

When interpreting these results one should consider some limitations and strengths of the present study. First, this was an observational study so no conclusions can be made about causality. Second, we included only clinically stable individuals few of whom had preexisting lung disease, and due to this selection bias, our findings may not necessarily be valid for the CKD population as a whole. Third, we did not investigate confounders such as volume overload, subclinical pulmonary edema and interstitial fibrosis, which are common in patients with advanced CKD $[3,5,6]$. On the other hand, to the best of our knowledge, this is the first study exploring association of pulmonary dysfunction with mortality in extensively phenotyped individuals over a broad range of GFR categories.

\section{Conclusion}

Impaired lung function, especially restrictive lung dysfunction, is a common feature of advanced CKD that associates with severity of renal failure, presence of PEW, inflammation and CVD, and with 5-year all-cause and CVD-related mortality. The prevalence of restrictive lung function increased in proportion to the number of comorbid conditions, PEW, inflammation and CVD, being present concomitantly, from $13 \%$ in patients with none of these conditions to $64 \%$ when three of them were present. Further studies in larger cohorts of CKD patients on causes and consequences of lung dysfunction, especially restrictive lung function, are warranted to confirm these findings.

\section{Disclosure Statement}

Bengt Lindholm is employed by Baxter Healthcare Corporation. None of the other authors declare any conflict of interest.

\section{Acknowledgements}

We thank all patients and healthy subjects who participated in present study, and those who carried out the extensive clinical and laboratory work at the clinical investigational unit and the Renal Laboratory at Department of Renal Medicine, and at the Department of Clinical Physiology, Karolinska University Hospital Huddinge. This study was supported by a grant from Baxter Healthcare to Baxter Novum, Department of Clinical Science, Intervention and Technology, Karolinska Institutet. Peter Stenvinkel's research benefited from support from Amgen Inc., Karolinska Institutet Diabetes Theme Center, Swedish Research Council, Martin Rind Foundation, Njurfonden, and Westmans Foundation. 


\section{Kidney \\ Blood Pressure Research}

\section{References}

1 Xu J, Murphy SL, Kochanek KD, Bastian BA: Deaths: Final Data for 2013. Natl Vital Stat Rep 2016;64:1-119.

- 2 Ford ES, Mannino DM, Wheaton AG, Giles WH, Presley-Cantrell L, Croft JB: Trends in the prevalence of obstructive and restrictive lung function among adults in the United States: findings from the National Health and Nutrition Examination surveys from 1988-1994 to 2007-2010. Chest 2013;143:1395-1406.

3 Bush A, Gabriel R: The lungs in uraemia: a review. J R Soc Med 1985;78:849-855.

4 Navaneethan SD, Mandayam S, Arrigain S, Rahman M, Winkelmayer WC, Schold JD: Obstructive and Restrictive Lung Function Measures and CKD: National Health and Nutrition Examination Survey (NHANES) 2007-2012. Am J Kidney Dis 2016,68:414-421.

5 Zoccali C, Tripepi R, Torino C, Bellantoni M, Tripepi G, Mallamaci F: Lung congestion as a risk factor in endstage renal disease. Blood Purif 2013;36:184-191.

-6 Prezant DJ: Effect of uremia and its treatment on pulmonary function. Lung 1990;168:1-14.

7 Nakade Y, Toyama T, Furuichi K, Kitajima S, Ohkura N, Sagara A, Shinozaki Y, Hara A, Kitagawa K, Shimizu M, Iwata Y, Oe H, Nagahara M, Horita H, Sakai Y, Kaneko S, Wada T: Impact of kidney function and urinary protein excretion on pulmonary function in Japanese patients with chronic kidney disease. Clin Exp Nephrol 2014;18:763-769.

8 Sin DD, Wu L, Man SF: The relationship between reduced lung function and cardiovascular mortality: a population-based study and a systematic review of the literature. Chest 2005;127:1952-1959.

-9 Friedman GD, Klatsky AL, Siegelaub AB: Lung function and risk of myocardial infarction and sudden cardiac death. N Engl J Med 1976;294:1071-1075.

10 Nascimento MM, Qureshi AR, Stenvinkel P, Pecoits-Filho R, Heimburger O, Cederholm T, Lindholm B, Barany $\mathrm{P}$ : Malnutrition and inflammation are associated with impaired pulmonary function in patients with chronic kidney disease. Nephrol Dial Transplant 2004;19:1823-1828.

11 Yoon SH, Choi NW, Yun SR: Pulmonary dysfunction is possibly a marker of malnutrition and inflammation but not mortality in patients with end-stage renal disease. Nephron Clin Pract 2009;111:c1-6.

12 Levey AS, Stevens LA, Schmid CH, Zhang YL, Castro AF, 3rd, Feldman HI, Kusek JW, Eggers P, Van Lente F, Greene T, Coresh J, Ckd EPI: A new equation to estimate glomerular filtration rate. Ann Intern Med 2009;150:604-612.

13 Chapter 1: Definition and classification of CKD. Kidney Int Suppl (2011) 2013;3:19-62.

14 Isoyama N, Leurs P, Qureshi AR, Bruchfeld A, Anderstam B, Heimburger O, Barany P, Stenvinkel P, Lindholm B: Plasma S100A12 and soluble receptor of advanced glycation end product levels and mortality in chronic kidney disease Stage 5 patients. Nephrol Dial Transplant 2015;30:84-91.

15 Stenvinkel P, Heimburger O, Paultre F, Diczfalusy U, Wang T, Berglund L, Jogestrand T: Strong association between malnutrition, inflammation, and atherosclerosis in chronic renal failure. Kidney Int 1999;55:18991911.

16 Crapo RO, Morris AH, Gardner RM: Reference spirometric values using techniques and equipment that meet ATS recommendations. Am Rev Respir Dis 1981;123:659-664.

17 Rabe KF, Hurd S, Anzueto A, Barnes PJ, Buist SA, Calverley P, Fukuchi Y, Jenkins C, Rodriguez-Roisin R, van Weel C, Zielinski J, Global Initiative for Chronic Obstructive Lung D: Global strategy for the diagnosis, management, and prevention of chronic obstructive pulmonary disease: GOLD executive summary. Am J Respir Crit Care Med 2007;176:532-555.

-18 Qureshi A, Alvestrand A, Danielsson A, Divino-Filho J, Gutierrez A, Lindholm B, Bergström J: Factors predicting malnutrition in hemodialysis patients: a cross-sectional study. Kidney Int 1998;53:773-782.

19 Durnin JV, Womersley J: Body fat assessed from total body density and its estimation from skinfold thickness: measurements on 481 men and women aged from 16 to 72 years. Br J Nutr 1974;32:77-97.

20 Siri WE: Body composition from fluid space and density; analysis and methods. Nutrition 1993;9:480-491.

21 Kyle UG, Schutz Y, Dupertuis YM, Pichard C: Body composition interpretation. Contributions of the fat-free mass index and the body fat mass index. Nutrition 2003;19:597-604.

22 D’Agostino RB, Sr., Vasan RS, Pencina MJ, Wolf PA, Cobain M, Massaro JM, Kannel WB: General cardiovascular risk profile for use in primary care: the Framingham Heart Study. Circulation 2008;117:743753. 


\section{Kidney \\ Blood Pressure Research}

-23 Latouche A: A competing risk analysis should report results on all cause-specific hazards and cumulative incidence functions. J Clin Epidemiology 2013;66:648-653.

24 Jason PF, Gray RJ: A Proportional Hazards Model for the Subdistribution of a Competing Risk. Journal of the American Statistical Association 1999;94:496-509.

25 Danielsson P, Olafsdottir IS, Benediktsdottir B, Gislason T, Janson C: The prevalence of chronic obstructive pulmonary disease in Uppsala, Sweden--the Burden of Obstructive Lung Disease (BOLD) study: crosssectional population-based study. Clin Respir J 2012;6:120-127.

26 Lundbäck B, Lindberg A: COPD - prevalence and incidence; in Larsson K (ed): Chronic Obstructive Pulmonary Disease (COPD). Stockholm, Studentlitteratur AB, 2014, Chapter 3, pp 45-63.

-27 Backman H, Eriksson B, Hedman L, Stridsman C, Jansson SA, Sovijarvi A, Lindberg A, Ronmark E, Lundback B: Restrictive spirometric pattern in the general adult population: Methods of defining the condition and consequences on prevalence. Respir Med 2016;120:116-123.

28 Johnston AK, Mannino DM, Hagan GW, Davis KJ, Kiri VA: Relationship between lung function impairment and incidence or recurrence of cardiovascular events in a middle-aged cohort. Thorax 2008;63:599-605.

29 Huiart L, Ernst P, Suissa S: Cardiovascular morbidity and mortality in COPD. Chest 2005;128:2640-2646.

30 Anthonisen NR, Connett JE, Kiley JP, Altose MD, Bailey WC, Buist AS, Conway WA, Jr., Enright PL, Kanner RE, O'Hara P, et al.: Effects of smoking intervention and the use of an inhaled anticholinergic bronchodilator on the rate of decline of FEV1. The Lung Health Study. JAMA 1994;272:1497-1505.

-31 Ezzati M, Henley SJ, Thun MJ, Lopez AD: Role of smoking in global and regional cardiovascular mortality. Circulation 2005;112:489-497.

-32 Sunyer J, Ulrik CS: Level of FEV1 as a predictor of all-cause and cardiovascular mortality: an effect beyond smoking and physical fitness? Eur Respir J 2005;25:587-588.

33 National Center for Chronic Disease Prevention and Health Promotion (US) Office on Smoking and Health. The Health Consequences of Smoking - 50 Years of Progress: A Report of the Surgeon General. Atlanta (GA): Centers for Disease Control and Prevention (US); 2014. Section 8, Cardiovascular Diseases. Available from: https://www.ncbi.nlm.nih.gov/books/NBK294323/.

-34 Hozawa A, Billings JL, Shahar E, Ohira T, Rosamond WD, Folsom AR: Lung function and ischemic stroke incidence: the Atherosclerosis Risk in Communities study. Chest 2006;130:1642-1649.

35 Schroeder EB, Welch VL, Couper D, Nieto FJ, Liao D, Rosamond WD, Heiss G: Lung function and incident coronary heart disease: the Atherosclerosis Risk in Communities Study. Am J Epidemiol 2003;158:11711181.

36 Bark H, Heimer D, Chaimovitz C, Mostoslovski M: Effect of chronic renal failure on respiratory muscle strength. Respiration 1988;54:153-161.

-37 Bolton CE, Schumacher W, Cockcroft JR, Timpson NJ, Smith GD, Gallacher J, Rumley A, Lowe GD, Ebrahim S, Shale DJ, Ben-Shlomo Y: The CRP genotype, serum levels and lung function in men: the Caerphilly Prospective Study. Clin Sci (Lond) 2011;120:347-355.

-38 Jiang R, Burke GL, Enright PL, Newman AB, Margolis HG, Cushman M, Tracy RP, Wang Y, Kronmal RA, Barr RG: Inflammatory markers and longitudinal lung function decline in the elderly. Am J Epidemiol 2008;168:602-610.

-39 Fogarty AW, Jones S, Britton JR, Lewis SA, McKeever TM: Systemic inflammation and decline in lung function in a general population: a prospective study. Thorax 2007;62:515-520.

40 Hancox RJ, Gray AR, Sears MR, Poulton R: Systemic inflammation and lung function: A longitudinal analysis. Respir Med 2016;111:54-59.

41 Mannino DM, Ford ES, Redd SC: Obstructive and restrictive lung disease and markers of inflammation: data from the Third National Health and Nutrition Examination. Am J Med 2003;114:758-762.

42 Engstrom G, Lind P, Hedblad B, Wollmer P, Stavenow L, Janzon L, Lindgarde F: Lung function and cardiovascular risk: relationship with inflammation-sensitive plasma proteins. Circulation 2002;106:25552560.

43 Ross R: Atherosclerosis--an inflammatory disease. N Engl J Med 1999;340:115-126.

44 Libby P, Ridker PM, Maseri A: Inflammation and atherosclerosis. Circulation 2002;105:1135-1143. 


\section{Kidney \\ Blood Pressure Research}

-45 Koenig W, Sund M, Frohlich M, Fischer HG, Lowel H, Doring A, Hutchinson WL, Pepys MB: C-Reactive protein, a sensitive marker of inflammation, predicts future risk of coronary heart disease in initially healthy middle-aged men: results from the MONICA (Monitoring Trends and Determinants in Cardiovascular Disease) Augsburg Cohort Study, 1984 to 1992. Circulation 1999;99:237-242.

-46 Danesh J, Whincup P, Walker M, Lennon L, Thomson A, Appleby P, Gallimore JR, Pepys MB: Low grade inflammation and coronary heart disease: prospective study and updated meta-analyses. BMJ 2000;321:199-204.

-47 Ridker PM, Rifai N, Rose L, Buring JE, Cook NR: Comparison of C-reactive protein and low-density lipoprotein cholesterol levels in the prediction of first cardiovascular events. N Engl J Med 2002;347:15571565.

48 Sevenoaks MJ, Stockley RA: Chronic Obstructive Pulmonary Disease, inflammation and co-morbidity--a common inflammatory phenotype? Respir Res 2006;7:70.

49 Sin DD, Man SF: Why are patients with chronic obstructive pulmonary disease at increased risk of cardiovascular diseases? The potential role of systemic inflammation in chronic obstructive pulmonary disease. Circulation 2003;107:1514-1519.

50 Thomsen M, Dahl M, Lange P, Vestbo J, Nordestgaard BG: Inflammatory biomarkers and comorbidities in chronic obstructive pulmonary disease. Am J Respir Crit Care Med 2012;186:982-988.

51 Andreas S, Anker SD, Scanlon PD, Somers VK: Neurohumoral activation as a link to systemic manifestations of chronic lung disease. Chest 2005;128:3618-3624.

-52 Fouque D, Kalantar-Zadeh K, Kopple J, Cano N, Chauveau P, Cuppari L, Franch H, Guarnieri G, Ikizler TA, Kaysen G, Lindholm B, Massy Z, Mitch W, Pineda E, Stenvinkel P, Trevino-Becerra A, Wanner C: A proposed nomenclature and diagnostic criteria for protein-energy wasting in acute and chronic kidney disease. Kidney Int 2008;73:391-398.

53 Sumida K, Kwak L, Grams ME, Yamagata K, Punjabi NM, Kovesdy CP, Coresh J, Matsushita K: Lung Function and Incident Kidney Disease: The Atherosclerosis Risk in Communities (ARIC) Study. Am J Kidney Dis 2017;70:675-685. 